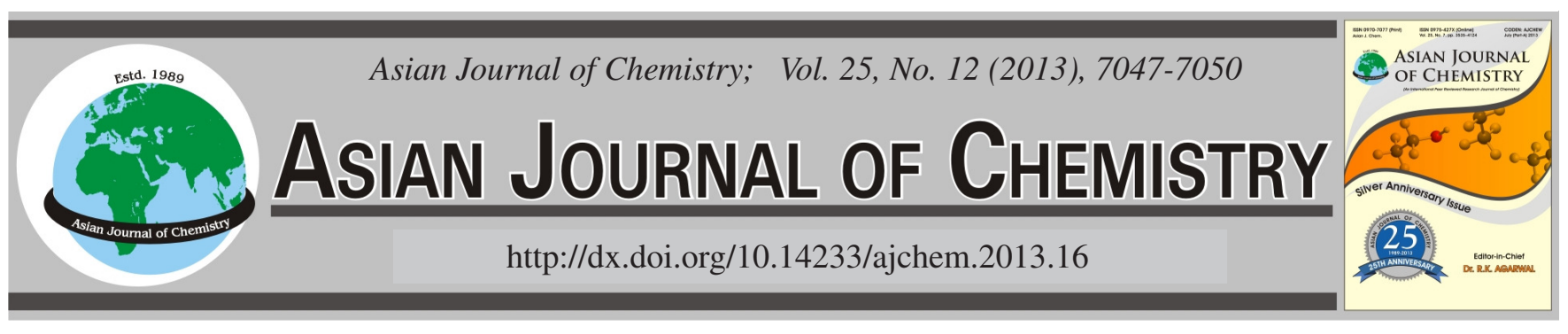

\title{
Radiological Assessment of the Dose Distribution Around Reactor Pressure Vessel $\dagger$
}

Geun-Ho Kim", Tae-Hyoung Kim, Byung-Seon Choi, Kwan-Seong Jeong, Donguun Hyun and Jeikwon Moon

Decontamination and Decommissioning Research Division, Korea Atomic Energy Research Institute, 989-111 Daedeok-daero, Yuseong-gu, Daejeon 305-353, Republic of Korea

*Corresponding author: Fax: +82 42 8682975; E-mail: ghkim7@kaeri.re.kr

AJC-13638

For a reasonable design of a decommissioning scenario, the dose distribution around the reactor pressure vessel of a commercial nuclear
power plant (NPP) was assessed preferentially using an $\mathrm{MCNP}$ code based on the concentration of ${ }^{60} \mathrm{Co}$. The regions of the dose calculation
were composed of two parts; one is between the reactor pressure vessel and the biological shield of a cylindrical-type and the other is at
the reactor pressure vessel pool of a rectangular-type. The highest dose value was $22.9 \mathrm{~Sv} / \mathrm{h}$ at $4.35 \mathrm{~m}$ from the bottom of the reactor
pressure vessel and the lowest dose value was $10.8 \mathrm{mSv} / \mathrm{h}$ at the top of the biological shield. It was shown that the dose is so high that
workers could not work around the reactor pressure vessel without radiation protective actions based on the domestic criteria (100 $\mathrm{mSv} /$
$5 \mathrm{yrs}$ and $50 \mathrm{mSv} / \mathrm{yr}$ ).

Key Words: Decommissioning, Reactor pressure vessel, Biological shield, Dose distribution, MCNP.

ᄂ - - - - - - - - - - - - - - - - - - - - - - - - - -

\section{INTRODUCTION}

The first commercial nuclear power plant in Korea has been operating since 1978 and 23 units nuclear power plants are currently in operation. However, the design life of 12 units will end within 2030 and the design life of KORI-1 and WOLSONG-1 already ended in 2007 and 2012, respectively. KORI-1 was granted an extended life to 2018, but WOLSONG1 remains undecided (Table-1). Although the Korea Atomic Energy Research Institute (KAERI) carried out the decommissioning of research reactors from 1999 to 2012, there remains no decommissioning experience for domestic commercial nuclear power plants. Therefore, the development of a decommissioning technology is required for the coming domestic commercial nuclear power plant decommissioning.

Meanwhile, to ensure safety by eliminating the various risk factors and improve the economics by the establishment of costcutting measures, a radiological assessment is needed for the decommissioning of an nuclear power plant after shutdown, as differs from an industrial facility. According to the US DOE report, the radiological risk in decontamination and decommissioning activity was $67 \%$ and because the radiological risk is closely related with the dose exposure of workers, a reasonable scenario considering the radiological risk is needed to reduce the exposure to workers. Thus a radiological assessment is required for designing a reasonable decommissioning scenario.

\begin{tabular}{cccccc}
\multicolumn{6}{c}{ TABLE-1 } \\
\multicolumn{5}{c}{$\begin{array}{c}\text { STATUS OF DOMESTIC NPP PREDICTED DESIGN } \\
\text { LIFE TERMINATION WITHIN 2030 }\end{array}$} \\
\hline Unit & $\begin{array}{c}\text { Starting } \\
\text { time }\end{array}$ & $\begin{array}{c}\text { Ending } \\
\text { time }\end{array}$ & $\begin{array}{c}\text { Capacity } \\
\text { (MWe) }\end{array}$ & Type & Note \\
\hline KR1* & 1978 & 2007.06 & 587 & PWR & $\begin{array}{c}\text { Extension life } \\
\text { (10 yrs) }\end{array}$ \\
WS1 & 1983 & 2012.11 & 679 & PHWR & Uncertain \\
KR2 & 1983 & 2023.04 & 650 & PWR & \\
KR3 & 1985 & 2024.09 & 950 & PWR & \\
YK1 & 1986 & 2025.12 & 950 & PWR & \\
KR4 & 1986 & 2025.08 & 950 & PWR & \\
WS2 & 1997 & 2026.11 & 700 & PHWR & \\
YK2 & 1987 & 2026.09 & 950 & PWR & \\
WJ1 & 1988 & 2027.12 & 950 & PWR & \\
WS3 & 1998 & 2027.12 & 700 & PHWR & \\
WJ2 & 1989 & 2028.12 & 950 & PWR & \\
WS4 & 1999 & 2029.02 & 700 & PHWR & \\
\hline *KORI-1 was re-operated from 2008 & \multicolumn{7}{c}{}
\end{tabular}

The stages of the decommissioning plan are generally divided into two parts: one is the radiological survey and characterization and the other is the establishment of the decommissioning plan itself. A radiological assessment for decommissioning can then be divided into the assessment of the radioactivity inventory of the main components and a space dose assessment of the facility ${ }^{2}$. In particular, to design the

$†$ Presented to the 4th International Symposium on Applications of Chemical and Analytical Technologies in Nuclear Industries, Daejeon, Korea 
decommissioning scenario under the ALARA principle and to calculate the exposure dose rate for workers, the assessment of the space dose of the facility is important.

In this study, the space dose distribution around the RPV and the biological shield in Kori-1, which are the main components in an nuclear power plant, was assessed for utilization of a reasonable design of the decommissioning scenario.

\section{EXPERIMENTAL}

The study areas were selected from the following assumptions: First, the radiation has had no effect outside of the biological shield. Second, there was no effective valid workspace for decommissioning except for the selected areas. The modeling and simulation were conducted by following three main steps.

Geometrical structure modeling: The RPV (Red) is an overall cylindrical-type structure and its head and bottom are a hemispherical-type. The height, diameter and maximum thickness of the RPV are $1,147 \mathrm{~cm}, 169 \mathrm{cmand} 16.8 \mathrm{~cm}$, respectively. Two pairs of nozzles are positioned at the upper part of the RPV. The biological shield (green) can be divided into two parts, a lower part and an upper part: The lower part is a cylindrical-type structure with a range of thickness of 200 to $267 \mathrm{~cm}$. The upper part is a rectangular-type with a thickness of about $30 \mathrm{~cm}$. The internal size of the upper part is $860 \times 670 \times$ $700 \mathrm{~cm}$ and the lower part is $\phi 250 \times 1,250 \mathrm{~cm}$. The materials of the RPV and biological shield are carbon steel $\left(7.86 \mathrm{~g} / \mathrm{cm}^{3}\right)$ and concrete $\left(2.24 \mathrm{~g} / \mathrm{cm}^{3}\right)$, respectively. The data of geometrical structure are based on the blue print of the nuclear power plant and the geometrical model is shown in Fig. 1.

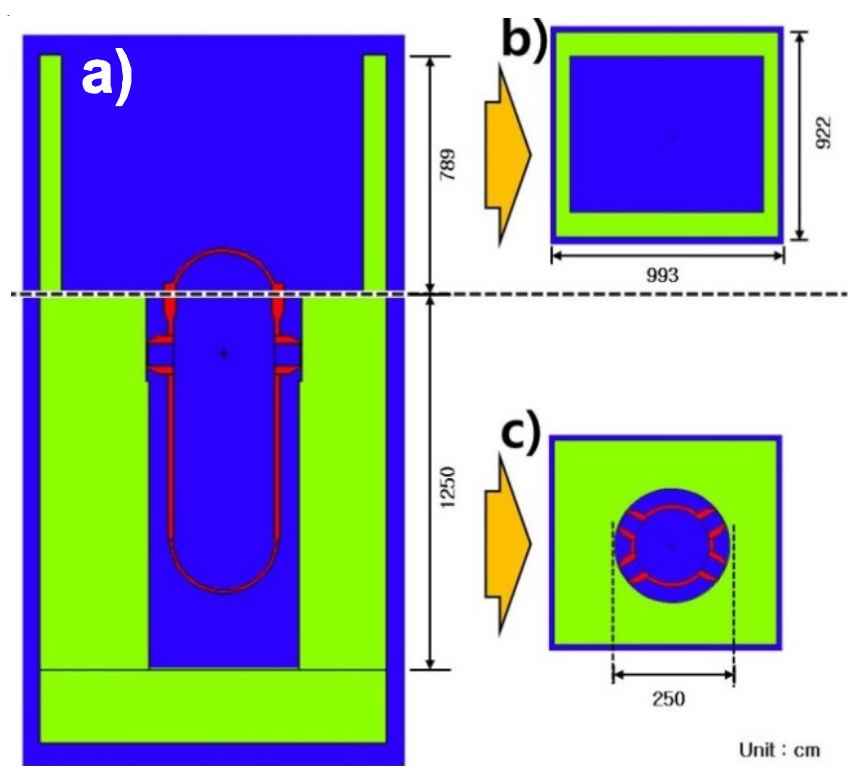

Fig. 1. Geometrical model of KORI-1 RPV and biological shield; (a: vertical cross section (Z-axis), b: horizontal cross section at the RPV pool (X-Y plate)andc: horizontal cross section at the nozzle area)

Source modeling: $\mathrm{A}{ }^{60} \mathrm{Co}$ nuclide was chosen as the main effective radio nuclide because it is a relativity long-lived nuclide among the generated radio nuclides during the decommissioning and contributes greatly to the exposure dose of workers. The concentration of ${ }^{60} \mathrm{Co}$ at the reactor core was obtained from the existing research data ${ }^{3}$. In this study, in order to obtain the value of the radioactive inventory as MCNP input data, it was assumed that the nuclear power plant operated for 40 years and cooled for 5 years after shutdown.

For the reasonable simulation, the active reactor core was divided into 3 parts from top to bottom. In general, the value of the radioactive inventory at the center of the reactor core is about 1,000 times higher than the value at the end of the core ${ }^{4}$. The radioactive inventory of the RPV at Rancho Seco showed similar results ${ }^{5}$. In this study, it was assumed that the concentration of ${ }^{60} \mathrm{Co}$ in each part was changed stepwise, even though it originally had a continuous distribution and the value of the center part was 1,000 times higher than other parts, as shown in Fig. 2.
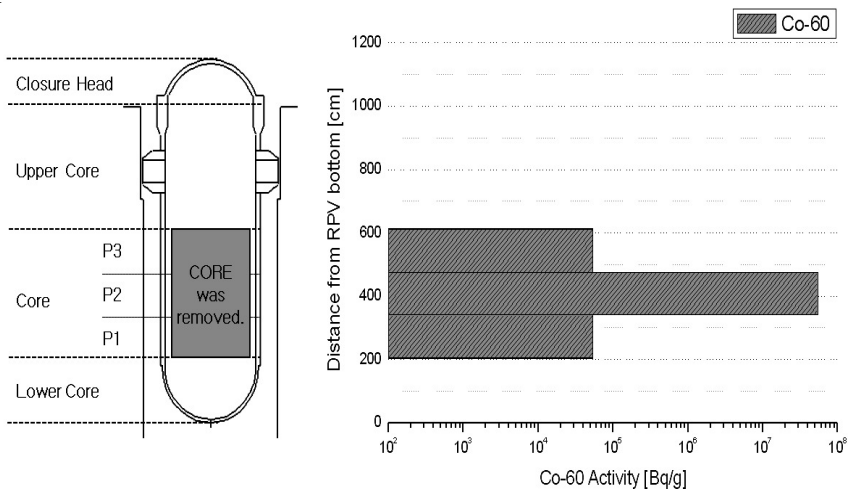

Fig. 2. Concentration of ${ }^{60} \mathrm{Co}$ nuclides at the RPV according to the location

Method of dose assessment: An MCNP code (build 1.40) was used to calculate the space dose distribution around the RPV and biological shield.

The regions of the dose calculation were composed of two parts; one is between the RPV and biological shield of the cylindrical-type (lower part) and the other is at the RPV pool of the rectangular-type (upper part) (Fig. 1-b,c). To calculate the space dose distribution, the regions of the upper and lower part were separated. The upper part was separated by a total of 3,808 measurement points $(17 \times 14 \times 16)$. The size of each measurement point was approximately $50.8 \mathrm{~cm} \times 50.1 \mathrm{~cm} \times$ $49.3 \mathrm{~cm}$ (Fig. 3-a). The lower part was separated by a total of 2,688 measurement points. The measurement points in the lower part were separated by the following steps: First, the lower parts are distinguished by 4 parts (Fig. 3-c) and second, the size of each point was separated by approximately $22.50^{\circ}$ $\times 29.8 \mathrm{~cm}$ (Fig. 3-b). The dose was calculated by an fmeshtally function for 6,496 dose measurement areas around the RPV and its surroundings. The dose calculation was calculated by the fmesh-tally function and the output of the fmesh-tally was converted into the dose rate by a flux-to-dose conversion factor from ICRP 60.

\section{RESULTS AND DISCUSSION}

To measure the space dose distribution around the RPV and biological shield, two regions were analyzed. One was the region between the RPV and biological shield, which is predicted to have a high dose rate and the other was at the top of the biological shield, which is used by most decommissioning workers. 

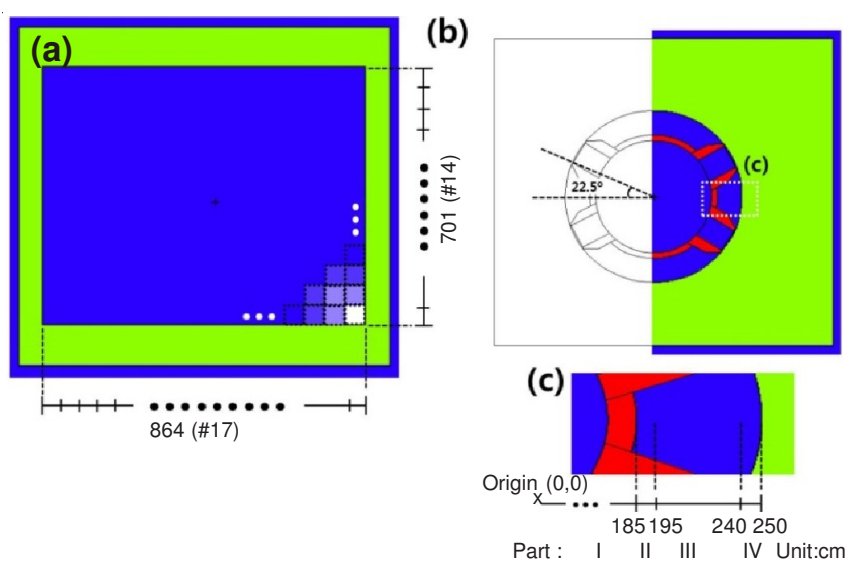

Fig. 3. Regions of the dose calculation; (a: measurement points at horizontal cross section at the RPV pool (X-Y plate), b: measurement points at horizontal cross section at the nozzle area, c: the separated parts at the RPV)

The dose rates between the RPV and biological shield were changed along the height of the RPV, as shown in Fig. 4.

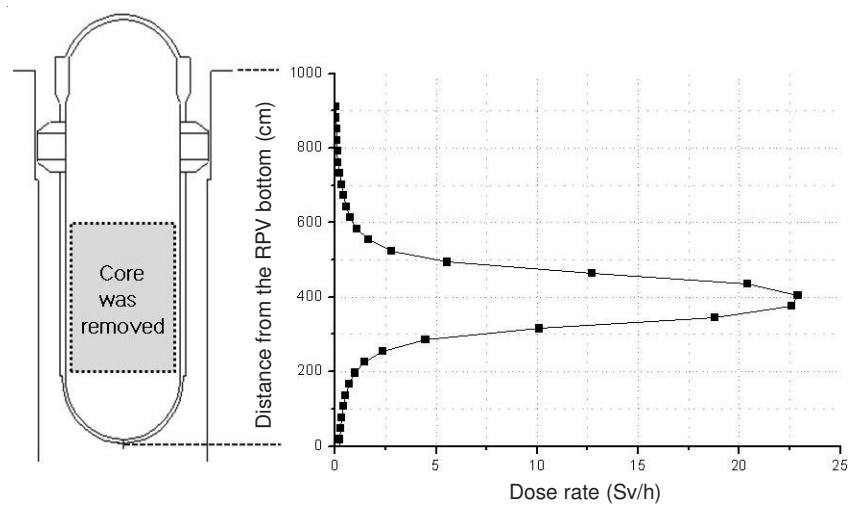

Fig. 4. Dose distribution between RPV and biological shield (z-axis direction)

The maximum dose value was $22.9 \mathrm{~Sv} / \mathrm{h}$ and the height of the maximum dose value point was $4.35 \mathrm{~m}$ from the bottom of the RPV. As it became far in the highest measurement point, the value became low (bell-shaped distribution). The reason for this is that the radioactive inventory at the center of the reactor core is high.

The dose rates at the top of the biological are shown in Fig. 5. The minimum value $(1.2 \mathrm{mSv} / \mathrm{h})$ was shown in the center of the upper area at the RPV headandmaximum values $(10.8 \mathrm{mSv} / \mathrm{h})$ were present at the center of both ends on the Y-axis (x : $70 \mathrm{~cm}, \mathrm{y}:-310 \mathrm{~cm}$ and $\mathrm{x}:-32 \mathrm{~cm}, \mathrm{y}: 341 \mathrm{~cm}$ ), respectively. These results mean that decommissioning work with direct access of the worker is permissible at above a height of about $1,000 \mathrm{~cm}$, but decommissioning work with direct access of the worker needs protective actions under a height of about $1,000 \mathrm{~cm}$. Fig. 5 also shows that the values (approximately $7.5 \mathrm{mSv} / \mathrm{h}$ ) of both ends on the $\mathrm{X}$-axis $(\mathrm{x}:-336.74 \mathrm{~cm}$, $y:-9.54 \mathrm{~cm}$ and $x: 323.76 \mathrm{~cm}, \mathrm{y}:-9.54 \mathrm{~cm})$ were lower than the values of both ends on the Y-axis. The reason for this is that two pairs of nozzles were located in near both ends of the $\mathrm{X}$-axis. The two nozzles functioned as a shielding materialandthus relatively low values were shown at both ends of the $\mathrm{X}$-axis.
Through these two results, it was confirmed that the working plate showed a relatively low activation and the area of the working plate, the height of which is $148-197 \mathrm{~cm}$ also had a low space dose. The workers will be exposed to relatively low radiation at this area. According to the domestic criteria, the dose limits for workers are $100 \mathrm{mSv} / 5 \mathrm{yrs}$ and $50 \mathrm{mSv} / \mathrm{yr}$. From these calculation results, it is apparent that the dose is so high that workers cannot work around the RPV without radiation protection. However, these values can be decreased through several methods such as decontamination steps to reduce the radioactivity and cooling time.
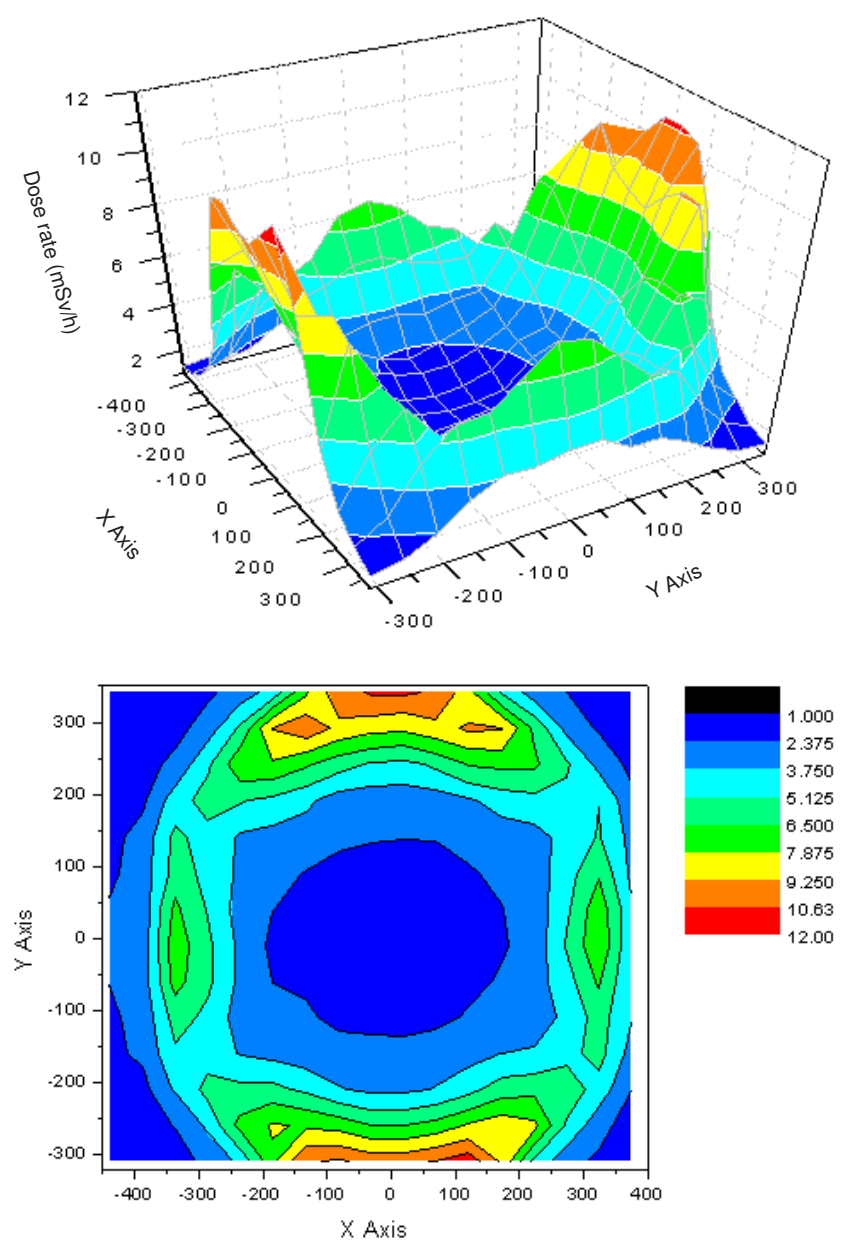

Fig. 5. Dose distribution at the top of the Biological shield

\section{Conclusion}

In this study, the distribution of dose rates around the RPV and biological shield at Kori-1 were calculated using an MCNP code and assessed. Assuming that the nuclear power plant operated for 40 years and cooled for 5 years after shutdown, the highest dose value was $22.9 \mathrm{~Sv} / \mathrm{h}$ at $4.35 \mathrm{~m}$ high in the RPV and the lowest dose value was $10.8 \mathrm{mSv} /$ hat the top of the biological shield. However, these values can be decreased through the several decontamination steps to reduce the radioactivity.

This result will be utilized as basic data to design a reasonable decommissioning scenario. A future plan is to assess the distribution of space dose including various factors such as the cooling time and decontamination methods and adding the internal structure of the RPV. 


\section{ACKNOWLEDGEMENTS}

This work was supported by the Nuclear Research and Development Program through the National Research Foundation of Korea funded by the Ministry of Education, Science and Technology and the Ministry of Knowledge Economy.

\section{REFERENCES}

1. United States Department Of Energy, Statistical Evaluation of DOE D \& D Occurrences, DOE/EH-0578 (1978)
2. A.L. Taboas, A.A. Moghissi and T.S. LaGuardia, The Decommissioning Handbook, American Nuclear Society ISBN:0-89448-041-3 (2004).

3. Korea Institute of Nuclear Safety, Study on the Safety Evaluation Method Development for D \& D of Nuclear Power Plant, KINS/HR-444 (2002).

4. Japan Atomic Energy Research Institute, Progress of JPDR Decommissioning Program-first Progress Report (December, 1986-July, 1987), JAERI (1987).

5. Electric Power Research Institute, Rancho Seco Reactor Vessel Segmentation Experience Report, EPRI 1015501 (2008). 